\title{
A geração de valor como um fator-chave à sustentabilidade: o caso de uma empresa brasileira $^{1}$
}

The value creation as a key to sustainability: the case of a Brazilian company

\section{La creación de valor como un factor clave para la sostenibilidad: el caso de una empresa brasileña}

\begin{abstract}
Ana Paula Ferreira Alves, Mestra em Administração pela Universidade Federal do Rio Grande do Sul (UFRGS). Endereço Profissional: Universidade Federal do Rio Grande do Sul. Rua Washington Luiz, 855 - Centro Histórico. CEP: 90010-460. Porto Alegre/ RS Telefone: (051) 330835368. URL da Homepage: http://www.ufrgs.br/escoladeadministracao. E-mail: anapfalves@gmail.com
\end{abstract}

Gabriele Volkmer, Mestra em Administração pela Universidade Federal do Rio Grande do Sul (UFRGS). Endereço Profissional: Universidade Federal do Rio Grande do Sul. Rua Washington Luiz, 855 - Centro Histórico. CEP: 90010-460. Porto Alegre/ RS Telefone: (051) 330835368. URL da Homepage: http://www.ufrgs.br/escoladeadministracao. E-mail: gabrielevolkmer@gmail.com

Marcio Luis Miron Jappe, Mestre em Administração pela Universidade Federal do Rio Grande do Sul (UFRGS). Endereço Profissional: Semente Negócios Sustentáveis Av. Cristovão Colombo, 100, Bairro Floresta, Porto Alegre - RS CEP: 90560-000.

Telefone: (048) 91155540. URL da Homepage: http://www.sementenegocios.com.br. E-mail: marcio.jappe@gmail.com

\section{RESUMO}

Lidar com a escassez de recursos naturais, as desigualdades sociais e outros desafios socioambientais faz parte da história da humanidade. A partir da década de 1970, o debate sobre as questões socioambientais aumentou, evidenciando um "paradigma da sustentabilidade", onde as preocupações com o meio ambiente e com a sociedade foram traduzidas em mudanças, a nível cultural, governamental e empresarial. Esse paradigma considera que as questões de sustentabilidade tornaram-se condição sine qua non para que as empresas existam no mercado. No entanto, as diferentes perspectivas têm dado espaço para várias abordagens a serem seguidas, distribuídas entre dois extremos: uma abordagem para "poupar recursos"; e uma abordagem para "utilização dos recursos de forma sustentável". Nesse contexto, esta pesquisa objetiva analisar os resultados da abordagem de "utilização dos recursos de forma sustentável" sobre a geração de valor de uma empresa. Para tanto, dados secundários foram avaliados para investigar o caso da Natura S/A. Os resultados confirmam a premissa que a "utilização dos recursos de forma sustentável" leva ao desenvolvimento de novos processos e produtos, melhorando o desempenho da firma, e, assim, gerando mais valor.

1 Artigo submetido em 18/02/2014, revisado em 28/04/2014, aceito em 28/09/2014 e divulgado em 30/06/2015 pelo Editor João Carlos Hipólito Bernardes do Nascimento, após double blind review.

GєCont, v.2, n. 1, Floriano-PI, Jan-Jun. 2015. 
Palavras-chave: paradigma da sustentabilidade; geração de valor das firmas; Natura.

\begin{abstract}
Dealing with scarcity of natural resources, social disparities and other social and environmental challenges have been part of human history. Since the 70's the debate about social and environmental issues has increased, highlighting the "sustainability paradigm", where concerns about the environment and the society were translated in changes at cultural, government and business levels. This paradigm considers that sustainability issues have become a sine qua non for companies exist in the market. However, the different perspectives have given room to several approaches to be taken, spread across two extremes: one the approach to "save resources"; and, the other, the approach to "use the resources in a sustainable way". In this context, this research aims to analyze the results of the approach of "use the resources in a sustainable way" on the firms' value creation. To do so, secondary data were evaluated to investigate the case of Natura, a cosmetics company. The results confirm the assumption that the "use the resources in a sustainable way" leads to the development of new processes and products, improving the firm performance, therefore generating more value.
\end{abstract}

Keywords: sustainability paradigm; firms'value generation; Natura.

\title{
RESUMEN
}

Lidiar con la escasez de recursos naturales, la desigualdad social y otros problemas sociales y ambientales es parte de la historia humana. Desde la década de los 70, el debate sobre las cuestiones sociales y ambientales ha aumentado, demostrando un "paradigma de la sostenibilidad", donde las preocupaciones sobre el medio ambiente y la sociedad se traducen en cambios, a lo nivel cultural, gubernamental e industrial. Este paradigma considera que los temas de sostenibilidad se han convertido en una condición sine qua non de las empresas existentes en el mercado. Sin embargo, las diferentes perspectivas han dado lugar a diferentes enfoques que se deben seguir, distribuidas entre dos extremos: un enfoque a "ahorrar recursos" y, el otro, un enfoque para la "utilización de los recursos de una manera sostenible”. En este contexto, esta investigación tiene como objetivo analizar los resultados de la "utilización de los recursos de una manera sostenible" en la creación de valor en una organización. Con este fin, se evaluaron los datos secundarios para investigar el caso de Natura S/A. Los resultados confirman la hipótesis de que el "uso de los recursos de una manera sostenible" conduce al desarrollo de nuevos procesos y productos, mejorando el desempeño de la empresa, generando así más valor.

Palabras clave: paradigma de la sostenibilidad; generación de valor de las empresas; Natura.

\section{INTRODUÇÃO}

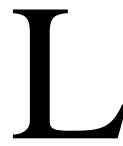

idar com a escassez de recursos naturais e com outros desafios ambientais tem sido parte da história humana desde o seu início, há milhões de anos. No entanto, o atual sistema capitalista de produção e consumo, amplamente disseminado no mundo, vem agravando o desperdício de recursos naturais (e também os problemas sociais). Nesse sentido, a partir da segunda metade do século XX, os movimentos

GєCont, v.2, n. 1, Floriano-PI, Jan-Jun. 2015. 
ambientalistas passaram a destacar os impactos no ambiente consequentes dos padrões de produção e de consumo em expansão no mundo, e questionar providências para reduzi-los ou extingui-los (NASCIMENTO, 2012). Além disso, a relação interdependente entre problemas ambientais e a desigualdade social tornou-se evidente, uma vez que a pobreza é considerada uma das principais causas e decorrências dos problemas ambientais do planeta (WCED, 1987). A questão ambiental deixou de ficar restrita ao meio natural e adentrou o espaço social (NASCIMENTO, 2012).

Dessa maneira, os impactos derivados do sistema capitalista deflagraram problemas ambientais, sociais e econômicos, salientando que esses modos de produção e consumo são socialmente injustos, ambientalmente desequilibrados e economicamente inviáveis (CLARO; CLARO; AMÂNCIO, 2008). O resultado da crescente conscientização global, sobre os problemas ambientais e sobre as questões socioeconômicas relacionadas com a pobreza, fomentou a geração do conceito de desenvolvimento sustentável (HOPWOOD; MELLOR; O'BRIEN, 2005). Junto à emergência de problemas socioambientais e de conceitos relacionados à sustentabilidade, as organizações passaram a ser pressionadas por diversos atores (incluindo a sociedade, governantes e entidades não governamentais) a incorporarem práticas ambientais e sociais em suas operações e estratégias.

Por conseguinte, empresas passaram a perceber a necessidade de considerar aspectos vinculados à sustentabilidade - que até então não faziam parte do interesse empresarial - bem como começaram a averiguar possíveis influências e impactos dessas questões nas suas operações (BRITO; BERARDI, 2010). Cabe salientar que a questão econômica não deve ser desprezada, visto que se entende que a empresa está contribuindo para a sustentabilidade quando sua atuação gera resultados positivos em termos econômicos, sociais e ambientais, beneficiando, ao mesmo tempo, a sociedade, o ambiente e a rentabilidade das empresas (ORSATO, 2006; CARVALHO, 2011). Nessa circunstância, práticas em sustentabilidade podem ser consolidadas como uma "licença de operação", um pré-requisito para a operação das empresas do século XXI.

Assim, de acordo com Orsato (2006), é preciso que o debate sobre a inserção de sustentabilidade nas empresas gire em torno de uma grande questão: "quando introduzir práticas pró-sustentabilidade nas operações e estratégias da empresa?". O aumento dessas discussões levou ao surgimento de um "paradigma da sustentabilidade", onde as preocupações socioambientais foram traduzidas em mudanças a nível institucional, legal e cultural. Entretanto, nem todas as organizações têm encontrado maneiras para associar a lucratividade com os esforços para um desenvolvimento mais sustentável (KIRON et al., 2012), apresentando sérias dificuldades em alinhar seus discursos e práticas gerenciais a uma estratégia de sustentabilidade (CLARO; CLARO; AMÂNCIO, 2008). Dessa forma, diferentes perspectivas têm dado espaço para várias abordagens a serem tomadas, distribuídas por dois extremos: a demanda para "salvar a natureza"; e a demanda para "usar recursos de forma sustentável”, que estaria alinhado ao conceito de sustentabilidade.

Diante dessas considerações, este artigo possui como objetivo analisar os resultados da abordagem de "utilização dos recursos de forma sustentável" sobre a geração de valor de uma firma. Para tanto, optou-se por estudar a empresa Natura S/A. A escolha do setor é justificada devido à sua significativa dimensão do mercado global e à sua conexão com o cotidiano de grande parte da população mundial, e, a empresa, porque, além de ser a líder em vendas do setor no Brasil, está listada na bolsa de valores, possuindo dados disponíveis para uma análise adequada da variação de seu valor de mercado ao longo dos anos. Além desta introdução, o artigo possui quatro seções: na seção dois, a revisão da literatura explora o paradigma orientado à sustentabilidade e os conceitos de firma e inovação; na seção três, expõem-se a metodologia do estudo; na seção quatro, apresentam-se os resultados da pesquisa; e, 
finalmente, na seção cinco são expostas as considerações finais, limitações do estudo e possibilidades de novas pesquisas.

\subsection{FUNDAMENTAÇÃO TEÓRICA}

\subsection{Paradigma Orientado à Sustentabilidade}

Nos últimos séculos, o meio ambiente era considerado variável externa à humanidade, que seria plenamente capaz de se regenerar. Os problemas ambientais eram tratados, comumente, como questões locais. Entretanto, os desafios ambientais sempre estiveram presentes na busca por melhores condições de sobrevivência das sociedades, principalmente, em função dos recursos finitos e escassos. Nessa mesma perspectiva, movimentos próambientais passaram a evidenciar que os modos de produção e consumo vigentes traziam em si grandes ameaças para o planeta como um todo - visto que a má administração dos recursos poderia levar uma sociedade ao colapso (DIAMOND, 2005). Essas evidências fizeram com que, por exemplo, a Suécia realizasse uma proposição ao Conselho Econômico e Social das Nações Unidas, em 1968, para um encontro mundial para a assinatura de um acordo internacional de redução da emissão dos gases responsáveis pelas chuvas ácidas sobre os países europeus (NASCIMENTO, 2012).

A discussão do meio ambiente como uma questão global, impactando em todos os cantos do planeta, vem ganhando importância desde a realização da Conferência das Nações Unidas em 1972, em Estocolmo, que reconheceu a importância da gestão ambiental e a utilização da avaliação ambiental como uma ferramenta de gestão (DUBOSE et al., 1995). Apesar de não tão forte, a ligação entre as questões ambientais e de desenvolvimento emergiu. O debate ganhou ainda mais espaço com a publicação do relatório do Clube de Roma "Limits to Growth", o qual enfatizou que a sociedade industrial estaria ultrapassando a maioria dos limites ecológicos dentro de uma questão de décadas, caso continuasse a promover o tipo de crescimento econômico registrado em 1960 e 1970 (MEBRATU, 1998). Além disso, o relatório sugeriu medidas para desacelerar o desenvolvimento industrial em países desenvolvidos e o crescimento da população nos países em desenvolvimento (NASCIMENTO, 2012). A interdependência entre questões ambientais e sociais tornou-se, então, evidente.

Diante desses argumentos, percebe-se que os modos de produção e consumo, que fomentaram o desenvolvimento humano por várias décadas, passaram a apresentar sinais irrefutáveis de uma crise ressaltada por problemas socioambientais, ameaçando o processo de desenvolvimento humano a médio e longo prazo (CDMAALC, 1991). Nesse contexto, reunindo as preocupações ambientais e questões socioeconômicas em um conceito guardachuva, tem-se o conceito de desenvolvimento sustentável, cuja definição mais difundida é a do relatório da Comissão Mundial para o Meio Ambiente e Desenvolvimento "Our Common Future". Publicado em 1987, o relatório estabelece o desenvolvimento sustentável como aquele que atende "às necessidades do presente sem comprometer a capacidade das gerações futuras de suprir suas necessidades" (WCED, 1987, p.43). Esta definição, em função de seu caráter amplo e vago, resultou em várias interpretações diferentes sobre o tema (CLARO; CLARO; AMÂNCIO, 2008), contribuindo para sua propagação mundial e apoiando uma mudança de paradigma (que compreenda claramente aspectos socioambientais). Ressalta-se o conceito triple bottom line de Elkington (2001), que alega que a sustentabilidade deve abranger, ao mesmo tempo, dimensões sociais, ambientais e econômicas. 
Em 1992, cinco anos após a reunião da Comissão, a "Cúpula da Terra" (mais conhecido como Rio'92) aconteceu no Rio de Janeiro, levando à produção de grandes documentos internacionais como a Declaração do Rio, Agenda 21 e convenções sobre a desertificação, a biodiversidade e as mudanças climáticas (que geraram o Protocolo de Kyoto). O legado mais importante da Cúpula foi a própria natureza do processo preparatório, que, na maioria dos países, envolveu a participação de todas as partes interessadas. Este processo levou o conceito de desenvolvimento sustentável a todos os cantos do mundo, expondo-o a questões como: O que isso realmente significa para cada comunidade? Como podemos ir além das generalidades e colocá-lo em prática? Como podemos saber se estamos nos movendo em direção a um mundo sustentável? (MEBRATU, 1998).

Assim, o século XXI cresceu sob três perspectivas: de contradição, de incerteza e de esperança - a contradição entre a crescente crise ambiental e a fraqueza das ações para sua mitigação; a incerteza em relação ao futuro da humanidade em meio a crises socioambientais; e, esperanças que as mudanças aconteçam e os padrões de comportamento da sociedade evoluam (NASCIMENTO, 2012). Portanto, surge um novo paradigma, orientado à sustentabilidade, representado por uma nova forma de gestão, onde as organizações integram a gestão ambiental e a responsabilidade social em seus objetivos, cumprindo além das exigências legais, em prol de uma consciência mais sustentável (TACHIZAWA, 2005). Para enfatizar a emergência do paradigma da sustentabilidade, aconteceu em Johanesburgo, em 2002, a Rio+10, uma conferência mais focada na regulação crescente da ação humana em nível internacional (RIBEIRO, 2001). Em 2012, ocorreu a Conferência Rio+20, no Rio de Janeiro, com o foco no desenvolvimento de uma economia verde (mais harmoniosa ao meio ambiente), no contexto do desenvolvimento sustentável e da erradicação da pobreza (UNITED NATIONS, 2012).

Em meio à emergência de problemas socioambientais e ao surgimento de conceitos relacionados à sustentabilidade, as organizações passaram a ser pressionadas pela sociedade, governantes e entidades não governamentais a incorporarem aspectos ambientais e sociais em suas operações. É preciso encarar os desafios socioambientais em sua total extensão no presente para preparar e garantir o futuro das organizações (EGRI; PIENFIELD, 2001). Nessa perspectiva, lidar com questões socioambientais tornou-se uma condição sine qua non para a maioria das empresas que transacionam em mercados. Pode-se alegar que as práticas relacionadas à sustentabilidade passaram a representar um pré-requisito para a operação das empresas do século XXI. No entanto, ao contrário do que aconteceu com o movimento da qualidade total, onde as empresas realizaram sua adesão voluntariamente com a expectativa de aumentar sua competitividade, a adoção de práticas de sustentabilidade por empresas ocorreu inicialmente em resposta a pressões da sociedade e a legislações mais rigorosas.

Por sua vez, o envolvimento das empresas com questões sociais e ambientais pode se tornar uma oportunidade de negócio, aumentando a qualidade de vida da sociedade e a preservação dos recursos naturais (CLARO; CLARO; AMÂNCIO, 2008). No geral, a percepção sobre a sustentabilidade pelas empresas está mudando, sendo vista como uma maneira para melhorar os aspectos técnicos e econômicos, ao contrário de uma visão mais conservadora, que entende que a conservação do meio ambiente e a redução dos problemas sociais implicam em custos adicionais (FERRO; BONACELLI; ASSAD, 2006). Assim, a introdução da sustentabilidade em práticas empresariais não deve ser vista como um aumento nos custos, mas sim uma oportunidade para inovar, ganhar competitividade, melhorar a imagem da empresa e reforçar a reputação no mercado - beneficiando, simultaneamente, a sociedade, o ambiente e a rentabilidade das empresas. Todavia, a maioria das empresas deverão se tornar "melhores cidadãos corporativos", investindo em fundações ou em projetos 
socioambientais. Somente poucas serão capazes de transformar o investimento no meio ambiente e na sociedade em fontes de vantagem competitiva (ORSATO, 2006).

Em um estudo realizado por Kiron et al. (2012), verificou-se que nem todas as empresas analisadas são capazes de lucrar com seus investimentos em sustentabilidade. Entretanto, os resultados sugerem que a maioria dessas está se esforçando para definir o que é sustentabilidade de uma forma que seja relevante para o seu negócio. Para as empresas que foram capazes de incluí-la em suas operações, os benefícios identificados apontam a redução de custos operacionais, aumento da receita, integridade da marca, engajamento dos funcionários e benefícios financeiros decorrentes de tais práticas. Considerando que as questões relacionadas à sustentabilidade não parecem ser mais uma opção, a maioria dos entrevistados alegou que os aspectos socioambientais são fatores críticos de grande relevância para que a empresa possa ser competitiva no mercado atual. $\mathrm{O}$ estudo conclui que as empresas vêm adotando iniciativas de sustentabilidade a um ritmo significativo nos últimos anos, independente de obter lucro ou vantagem competitiva a partir de tais iniciativas (KIRON et al., 2012). Nessa circunstância, Orsato (2006) ressalta que o debate sobre a inserção da sustentabilidade nas empresas deve ser desvinculado da questão "introduzir ou não introduzir" e passar para a nova pergunta "quando será realizada a introdução".

Diante dessas considerações, podem-se elencar dois pontos de vista em relação a como as empresas estão reagindo ao "paradigma da sustentabilidade": um focado em "salvar a natureza e a sociedade", respondendo às pressões da legislação, da sociedade, do governo e das organizações não-governamentais; e, a outra focada em inovar radicalmente para melhorar a utilização e a produtividade dos recursos naturais, de modo a minimizar os impactos sociais e ambientais decorrentes dessa extração desses recursos. De maneiras diferentes, empresas estão adotando e integrando práticas de sustentabilidade em seus negócios, tentando conciliar cada dimensão (econômica, social e ambiental) com a exploração do potencial da biodiversidade para gerar benefícios (FERRO; BONACELLI; ASSAD, 2006). Algumas empresas adotam uma abordagem orientada à minimização dos impactos socioambientais negativos através de programas e ações que não estão diretamente relacionadas ao desenvolvimento de sua atividade econômica principal - a abordagem de "salvar os recursos", salvar a natureza. Por seu turno, outras seguem uma abordagem que incorpora os princípios de sustentabilidade na essência das operações da firma - a abordagem da "utilização dos recursos de forma sustentável".

Desse modo, a partir das duas abordagens, algumas empresas se concentram em minimizar os seus impactos sociais e ambientais, adotando ações para reduzir as consequências das operações de seus negócios. Por sua vez, outras empresas aproveitam o uso dos recursos de forma sustentável para o desenvolvimento de inovações em seus negócios de modo a evitar que impactos desnecessários sejam gerados - e que recursos tenham que ser deslocados para reverter suas consequências. Ainda, pode-se notar que uma abordagem foca na resolução de problemas, enquanto que outra foca em ações que minimizem a criação desses problemas ou que evitem que sejam gerados. Reforçar a visão positiva para a integração da sustentabilidade nas operações das empresas, com foco na geração de valor, parece ser uma abordagem mais razoável em comparação com o aumento dos custos para salvar a natureza.

\subsection{Firma e Inovação}

A teoria evolucionária trouxe aos estudos econômicos a noção de dinamismo, frente à noção clássica de equilíbrio. Dado que um sistema está em movimento e, portanto, em desequilíbrio, a teoria evolucionária busca compreender e explicar o motivo da existência de tantas diferenças entre firmas, setores e países (ZAWISLAK, 1996). Nesse contexto, o 
desenvolvimento do sistema econômico acontece em períodos de mudança, e não em períodos de estabilidade (SCHUMPETER, 1985). As firmas são fundamentais para que essas mudanças aconteçam, uma vez que reúnem condições específicas para inovar. Firmas são agentes econômicos responsáveis pela produção e troca de bens, e sua existência se justifica porque podem fazer de forma diferente do que já existe no mercado. Cada firma caminha lado a lado com uma organização que auxilia sua operação - esta combinação de firma, que produz e transaciona no mercado, e organização, estrutura técnica que combina os recursos, permitindo que a firma a cumprir o seu papel pode ser denominada empresa.

Diante da dinâmica do sistema econômico, é preciso aprimorar constantemente as competências inovadoras das firmas com o objetivo de dotá-las de melhores condições para modificar ou reagir às mudanças no mercado (NELSON; WINTER, 2005). Por conseguinte, verifica-se que o desempenho superior de algumas firmas deriva da sua capacidade de inovar (e gerar valor). A inovação pode ser definida como a busca por novas maneiras para fazer (novas) coisas, organizando as firmas de modo diferente. De forma geral, compreende-se inovação como a exploração com sucesso de novas ideias (BESSANT, 2003). De acordo com Dosi (1988), uma inovação diz respeito à busca e descoberta, experimentação, desenvolvimento, imitação e adoção de novos produtos ou serviços, novos processos de produção e novos arranjos organizacionais. As firmas existem para inovar, e existem porque há inovação. Assim sendo, a inovação é a resposta ao fenômeno do desenvolvimento econômico (SCHUMPETER, 1985).

Desse modo, as vantagens competitivas das firmas resultam basicamente de sua habilidade em fazer coisas úteis, difíceis de serem imitadas e melhor do que seus concorrentes, o que reflete sua capacidade em inovar (PAVITT, 1992). Conforme as inovações vão sendo imitadas por outras firmas ou substituídas por outras inovações, os lucros diminuem. O processo contínuo de resolução de problemas e de busca por novas oportunidades - o processo de inovação - torna-se crucial para a sobrevivência da firma no mercado. O termo inovação, portanto, assume o sentido de processo dinâmico e interativo de mudança na busca por novas maneiras de organizar recursos (DAROIT; NASCIMENTO, 2004), resultante de processos de interação entre oportunidades de mercado, base de conhecimento e capacidades da própria empresa, bem como sistema externo de ciência e tecnologia.

A novidade de uma inovação deve possuir valor de uso e valor de troca, com intuito de gerar valor econômico, a partir de um processo de competição, que envolve diferenciações em técnicas, produtos e/ou formas de organização (DAROIT; NASCIMENTO, 2004; SCHUMPETER, 1942). Nessa perspectiva, a inovação gera valor e desloca a curva de produtividade a um patamar superior, por meio da socialização do progresso técnico (SCHUMPETER, 1942). O desenvolvimento econômico decorre da introdução de inovações, ou seja, novas formas de combinar os meios de produção (SCHUMPETER, 1912). A constante transformação das firmas resulta e é resultado de uma constante transformação no sistema como um todo, que evolui (SCHUMPETER, 1942). Se o sistema evolui, o ambiente se modifica, fazendo com que as firmas mudem em função de seu ambiente e de seu desempenho organizacional (NELSON; WINTER, 2005). Logo, as firmas concentram seus esforços em adquirir conhecimentos e capacidades que reforcem suas possibilidades de sobrevivência em um ambiente competitivo (NORTH, 1994).

A combinação de novas formas depende ainda do paradigma tecnológico existente, que define as oportunidades tecnológicas para o surgimento de mais inovações e alguns procedimentos básicos sobre como explorá-las. O paradigma tecnológico define contextualmente as necessidades a serem satisfeitas, assim como os princípios científicos utilizados para as tarefas e a tecnologia de material a ser empregada. De tal modo, os gargalos

GєCont, v.2, n. 1, Floriano-PI, Jan-Jun. 2015. 
tecnológicos, as oportunidades, as experiências e habilidades adquiridas, bem como as características específicas de cada atividade econômica, são ingredientes fundamentais ao processo de inovação. A aprendizagem inovadora é local e específica, visto que é um paradigma vinculado e ocorrido ao longo de trajetórias particulares. Essas trajetórias podem ser denominadas trajetórias tecnológicas - trocas econômicas e tecnológicas determinadas pelo paradigma (DOSI, 1988). A trajetória mostra a canalização de esforços em um determinado sentido em vez de outros (NELSON; WINTER, 2005; DOSI, 1988), ou seja, é a atividade do progresso tecnológico ao longo do paradigma.

Um paradigma técnico-econômico é uma combinação de produtos inter-relacionados e processos, inovações técnicas, organizacionais e gerenciais, incorporando um salto quântico no potencial de produtividade para todos ou a maior parte da economia, abrindo uma ampla gama de investimento e oportunidades de lucro. Essa mudança de paradigma implica uma nova combinação de vantagens técnicas e econômicas decisivas. É apenas quando a produtividade ao longo das antigas trajetórias mostra barreiras para o aumento dos lucros, ameaçando o futuro da firma, é que os altos riscos e custos de experimentar as novas tecnologias se justificam. As inovações podem parecer um meio para superar os gargalos específicos das velhas tecnologias. Entretanto, o novo elemento passa a adquirir dinâmica própria, permitindo que inovações sucessivas ocorram por meio de um processo interativo intenso voltado para o crescimento econômico (FREEMAN, PEREZ, 1988). "Uma vez que a nova tecnologia é amplamente adotada, a mudança é geralmente irreversível" (FREEMAN; PEREZ, 1988, p.58).

Perante os argumentos expostos neste referencial teórico, pode-se observar a evidência de um novo paradigma econômico, aquele que considera a sustentabilidade nas operações das firmas e nas suas respectivas organizações. Grande parte das empresas se concentra em reduzir seus impactos socioambientais negativos, com ações que minimizem consequências de suas operações. No entanto, algumas procuraram alternativas para aproveitar o uso econômico (de forma sustentável) dos recursos para o desenvolvimento de inovações e, assim, de novas trajetórias tecnológicas em mercados sustentáveis emergentes. É possível perceber que a adoção da última abordagem significa a criação de mais valor e expansão da firma, ao introduzir aspectos de sustentabilidade em seus processos, operações e estratégias; enquanto que a primeira abordagem representa maiores repasses de recursos e aumento do tamanho da organização dentro das firmas.

\section{PROCEDIMENTOS METODOLÓGICOS}

A presente pesquisa objetiva analisar os resultados da abordagem de "utilização dos recursos de forma sustentável" sobre a geração de valor de uma empresa. Diante do objetivo, a premissa de pesquisa se traduz na afirmação que a "utilização de recursos de forma sustentável" leva ao desenvolvimento de novos processos e novos produtos, o que melhora o desempenho da firma, gerando, assim, mais valor. Assim, optou-se pelo estudo de um caso, uma empresa que se encaixe na abordagem pesquisada, a partir da análise de dados secundários como principal fonte de evidência. Nesse sentido, a Natura S/A foi selecionada como contexto empresarial a ser analisado, em virtude de três critérios: (a) negociar ações no mercado; (b) sua representatividade no mercado brasileiro de higiene pessoal, perfumaria e cosméticos; e, (c) disponibilidade de acesso a informações acerca de seus produtos, seus processos e suas estratégias em relatórios, sites oficiais, blogs e estudos acadêmicos (por exemplo, CARVALHO; BARBIERI, 2013; CARVALHO, 2011; YAMIM et al., 2013; CECCATO, 2012; CONTADOR; STAL, 2011).

GєCont, v.2, n. 1, Floriano-PI, Jan-Jun. 2015. 
A pesquisa foi realizada em duas etapas: a primeira, com a finalidade de avaliar a adequação da empresa à proposta do estudo; e, a segunda, a fim de realizar a análise propriamente dita. Dessa forma, inicialmente, os sites e os relatórios anuais da empresa, bem como estudos acadêmicos, foram analisados, com intuito de verificar sua abordagem para o "paradigma da sustentabilidade". Essa análise preliminar buscou identificar se a empresa possui práticas reativas, respondendo às legislações, ou proativas, adotando ações em prol da sustentabilidade de modo voluntário. Em seguida, averiguou-se se a empresa tende a adotar práticas para "salvar a natureza" - iniciativas para proteger o meio ambiente e minimizar os problemas sociais de modo externo ao seu core business - ou tende a adotar uma abordagem de "utilização dos recursos de forma sustentável" - em uma relação direta de questões socioambientais com seus processos e com seu core business.

Uma vez realizada a primeira etapa e verificada a adequação da empresa, sucedeu-se a segunda etapa da pesquisa, onde foram analisados os dados financeiros e os relatórios anuais publicados na Bolsa de Valores de São Paulo (BM\&FBOVESPA), bolsa de valores onde a Natura S/A transaciona suas ações, também conhecida por Bovespa. A Natura é uma empresa de capital aberto desde junho de 2004, logo, foram considerados os períodos de junho de 2004 a junho de 2012 para realizar a análise. Dessa maneira, foram avaliadas as variações dos preços da ação de cada ano estudado, e também das margens EBITDA anuais, calculadas a partir da razão entre o Lucro Antes dos Juros, Impostos, Depreciação e Amortização (EBITDA, sigla em inglês) e a Receita Líquida de cada ano.

\section{ANÁLISE DOS DADOS}

\subsection{Uma abordagem diferente no setor de cosméticos}

O setor de produtos de higiene pessoal, perfumaria e cosméticos (HPPC) cresceu em média $10,5 \%$ ao ano nos últimos 15 anos. O Brasil ocupa o terceiro lugar no mercado mundial de produtos de HPPC, com $8,1 \%$ de participação mundial. Considerando apenas a América Latina, o país é líder de mercado, com aproximadamente $53 \%$ de participação no mercado latino. Dessa maneira, o mercado brasileiro apresenta tendências potenciais para crescer ainda mais, em virtude de fontes de princípios ativos e insumos, principalmente os de origem natural; utilização de tecnologia de ponta e consequente aumento da produtividade; avanços na regulamentação; e, aumento do consumo de produtos. Em 2011, o setor foi responsável pela origem de 2,9 milhões de oportunidades de trabalho, e seu faturamento, nesse período, girou em torno de $\mathrm{R} \$ 29,4$ bilhões no mercado nacional (ABIHPEC, 2013).

\subsubsection{Natura $S / A$}

A Natura S/A é a líder do setor de vendas diretas e líder do mercado de higiene, perfumaria e cosméticos no Brasil. É uma marca de origem brasileira, fundada em 1969 e, atualmente, está presente em sete países da América Latina e na França. Em 2004, a Natura passou a ser uma companhia de capital aberto, com ações listadas no Novo Mercado - o nível mais alto de governança corporativa da Bovespa, onde são negociadas as ações das empresas comprometidas com práticas de governança corporativa, além de regras mais rígidas do que as exigidas na legislação brasileira em termos de transparência e garantias aos investidores (CASTRO et al., 2009; REVISTA BOVESPA, 2004). Ainda, desde 2005, figura na listagem do Índice de Sustentabilidade Empresarial, cuja missão é induzir empresas a implantar melhores práticas de sustentabilidade e apoiar os investidores na tomada de decisão de investimentos socialmente responsáveis (ISE, 2013; CARVALHO, 2011). 
Desde 1974, a Natura utiliza o sistema de vendas diretas para expandir seu mercado, usando vendedoras especializadas, chamadas consultoras de beleza (CONTADOR; STAL, 2011; SILVA, 2007). As consultoras se tornaram o elo principal da Natura com o consumidor final e, atualmente, representam mais de 1,2 milhão de pessoas (CARVALHO; BARBIERI, 2013; CECCATO, 2012). A venda direta da Natura está baseada no desenvolvimento de uma marca forte junto a seus consumidores (RODRIGUES; RODRIGUES; OLIVEIRA, 2007). A empresa considera que os consultores são seus primeiros consumidores, visto que é por meio deles que os produtos chegam aos clientes finais (CECCATO, 2012). Nessa perspectiva, valoriza e aprimora o relacionamento entre funcionários, consultores e clientes. Ademais, para que exista uma relação harmoniosa baseada na confiança, a empresa investe em diversos tipos de treinamentos a seus consultores, para que estes possam orientar o processo de compra de modo a atender às necessidades e desejos dos clientes (CECCATO, 2012; CONTADOR; STAL, 2011).

Dentre os objetivos da empresa, constam promover a conservação e a utilização sustentável da biodiversidade, a valorização do patrimônio genético e dos conhecimentos tradicionais e o desenvolvimento das comunidades provedoras (NATURA, 2011). Sua proposta não inclui projetos isolados, mas sim uma política de responsabilidade socioambiental incorporada à sua gestão organizacional, colocando a sustentabilidade como elemento central em seus processos de inovação, através da adoção de processos de produção mais limpa, promoção dos princípios da sustentabilidade nos produtos e parceria e certificação da cadeia de fornecedores sob a perspectiva do desenvolvimento sustentável (SILVA, 2007; VILHA; QUADROS, 2012). A empresa, portanto, alega investir em soluções para os desafios socioambientais, com o intuito de transformá-los em oportunidades de negócios que gerem valor para todos (NATURA, 2011).

Em seus relatórios, a Natura ressalta que seu valor e sua longevidade estão vinculados à sua capacidade de contribuir para a evolução da sociedade e seu desenvolvimento sustentável (CARVALHO, 2011; NATURA, 2012). A Natura define sua política ambiental como uma das três vertentes de sua política de sustentabilidade, visando à ecoeficiência ao longo de sua cadeia de geração de valor, o que favorece a valorização da biodiversidade e de sua responsabilidade social. Para melhor difusão de suas práticas ambientais, a empresa utiliza uma "tabela ambiental" em seus produtos, apresentando informações que atribuem transparência sobre a origem de suas fórmulas e embalagens, incentivando, assim, o consumo consciente (CASTRO et al., 2009). Em relação a práticas sociais, evidencia-se a linha de produtos "Crer para Ver", lançada em 1995 e desenvolvida especialmente para o Programa Crer para Ver. Esse programa abrange ações focadas na melhoria da qualidade da educação, realizadas a partir do lucro dos produtos comercializados (INSTITUTO NATURA, 2013).

A Natura alega acreditar que as riquezas naturais do planeta, sua diversidade biológica e o patrimônio cultural da humanidade são bens de imenso valor, cuja utilização deve sempre incluir esforços no sentido de valorizá-los e conservá-los às gerações futuras. Alinhada a esse pensamento, a empresa lançou, em 2000, a linha Natura Ekos, onde a empresa se propõe a (re)descobrir, ressaltar, valorizar, preservar e difundir o patrimônio natural, cultural e social do Brasil, bem como a estimular o uso consciente dos recursos naturais do planeta. Os produtos Natura Ekos são biodegradáveis e utilizam vidros e embalagens que contêm material reciclado e refis que, além da diminuição do impacto ambiental, aumentam a competitividade da empresa, oferecendo economia e aproveitamento de embalagens. Em 2011, mais de 10 anos após o lançamento da linha, a Natura aumentou o reservatório de inovação e a concentração de ativos nas fórmulas, sendo estes ativos dosados de forma precisa para preservar a biodiversidade, gerar mais renda para as comunidades fornecedoras e entregar benefícios aos consumidores (NATURA EKOS, 2013).

GєCont, v.2, n. 1, Floriano-PI, Jan-Jun. 2015. 
A Natura possui o maior centro de pesquisa e desenvolvimento de cosméticos do Brasil. Um intercâmbio sistemático com outros centros de excelência em todo o mundo mantém os seus pesquisadores em contato permanente com os principais avanços nas áreas farmacêutica, química e bioquímica. A capacidade de inovar se tornou uma exigência deste tipo de mercado consumidor e um requisito para continuar no jogo. Considerando isto, a empresa busca unir de forma inovadora, a ciência e o conhecimento tradicional para pesquisar e transformar a riqueza da biodiversidade em novos produtos e conceitos (NASCIMENTO; MARX, 2001). A empresa contribui para a conservação dos ecossistemas a partir da exploração sustentável do território nacional para a inovação existente em seu patrimônio genético, cujo potencial pesquisa, revela e compartilha com a sociedade (NATURA, 2011).

Nesse sentido, a Natura tem sido reconhecida pelo alto grau de inovação de seus produtos e pela promoção do desenvolvimento sustentável, por meio da relação do homem com a natureza - a partir da responsabilidade na extração e do bom uso do patrimônio genético brasileiro, o que pode indicar a responsabilidade da organização com seu próprio país (CONTADOR; STAL, 2011; ABÍLIO, 2011). Assim, a empresa assegura buscar unir de forma inovadora, a ciência e o conhecimento tradicional para pesquisar e transformar a riqueza da biodiversidade em novos produtos e conceitos (NASCIMENTO; MARX, 2001). Durante o período de 2005 a 2010, a Natura lançou, em média, 168 produtos por ano. Nesse mesmo período, os investimentos em inovação mantiveram-se em torno de $3 \%$ da receita líquida da empresa, mas com aumento expressivo das vendas (CARVALHO, 2011). Diante dos argumentos apresentados, considera-se que a empresa adota a abordagem de "utilização dos recursos de forma sustentável".

\subsection{Abordagem diferenciada com resultados diferenciados}

Para constatar a efetiva geração de valor, os resultados financeiros da Natura S/A foram analisados em termos do valor gerado ao longo de um período de tempo significativo (mais especificamente, de 01 de junho de 2004 a 21 de junho de 2012, dado que a data inicial marca a abertura de capital da empresa no mercado de ações). Em primeiro lugar, realizou-se uma avaliação dos resultados da empresa e dos resultados do mercado, utilizando dados da bolsa de valores onde a empresa está listada e negocia suas ações, a Bolsa de Valores de São Paulo (BM\&FBOVESPA), ou Bovespa. Durante o período analisado, de uma forma geral, a Natura apresentou um desempenho superior contra a Bovespa (264\% da Natura contra 184\% de ganho da Bovespa).

No entanto, em uma tentativa de fornecer uma visão mais precisa dos dados, a taxa de inflação acumulada do período para os preços ao consumidor foi descontada da variação total dos preços das ações $(52,67 \%)$ (FMI, 2012). Dado que a Natura comercializa seus produtos em várias partes do mundo, considerou-se infrutífero seguir com uma tentativa de normalizar os dados ao empregar as diferentes taxas básicas de juros anuais do Brasil, que, no período de junho de 2012, era de 8\%. Embora seja difícil normalizar os dados para aperfeiçoar a análise, os dados sugerem que a Natura apresenta bom desempenho em termos de valor de mercado. Os resultados completos são apresentados no Gráfico 1. 


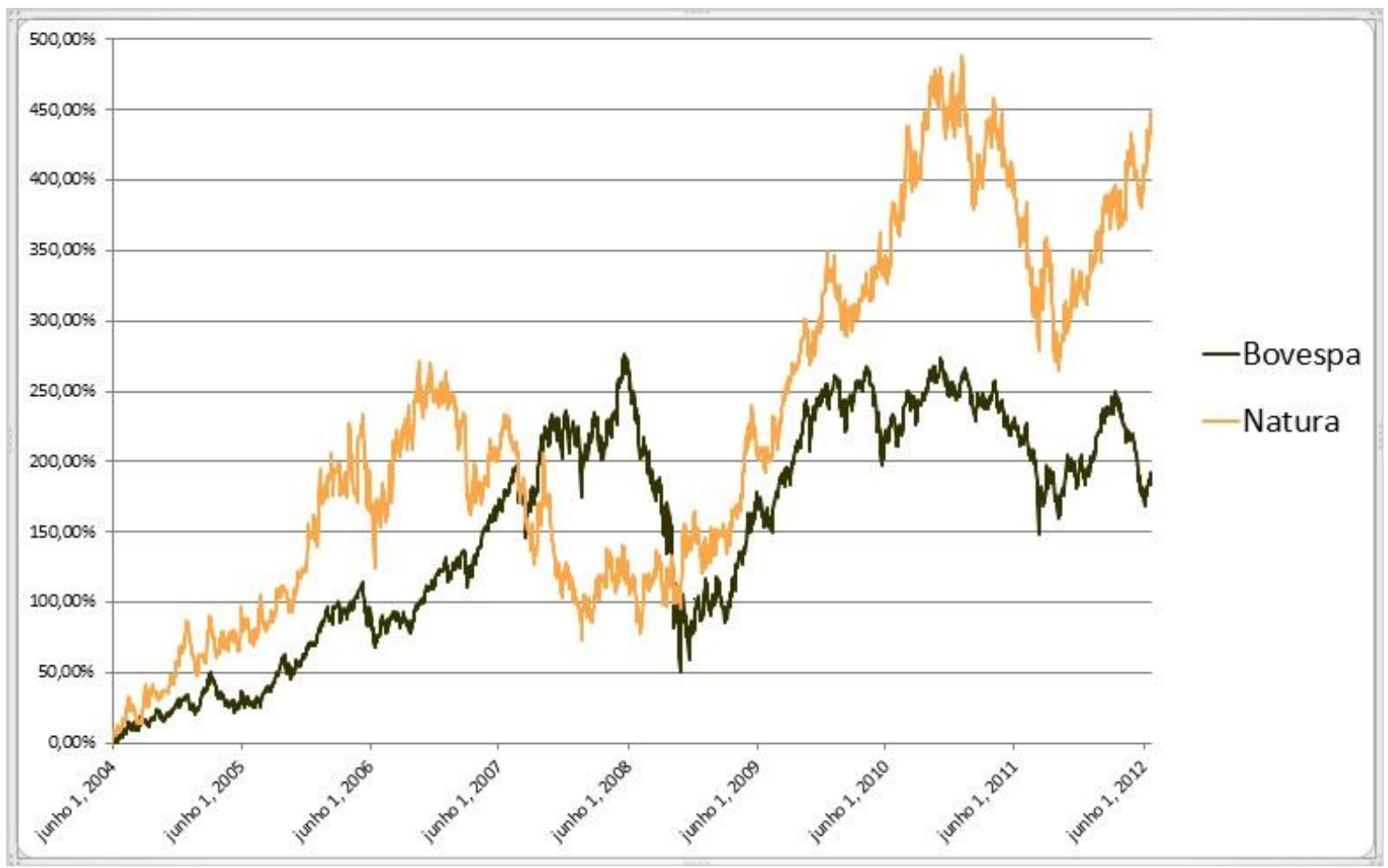

Gráfico 1. Comparação entre dados do mercado e da Natura

Além disso, foram comparadas as margens EBITDA, as margens de Lucro Antes dos Juros, Impostos, Depreciação e Amortização, da empresa durante o mesmo período analisado, visto que indicam a relação entre os custos da organização e o desempenho da empresa. Os dados apontam o bom desempenho da Natura no EBITDA médio e também sobre a margem corrente. O Gráfico 2 ilustra o EBITDA médio da empresa ao longo do período analisado. Por sua vez, o Gráfico 3 apresenta o EBITDA de cada ano, em recorte aleatoriamente selecionado, o que corrobora as indicações da análise do Desempenho das Ações de Mercado. 


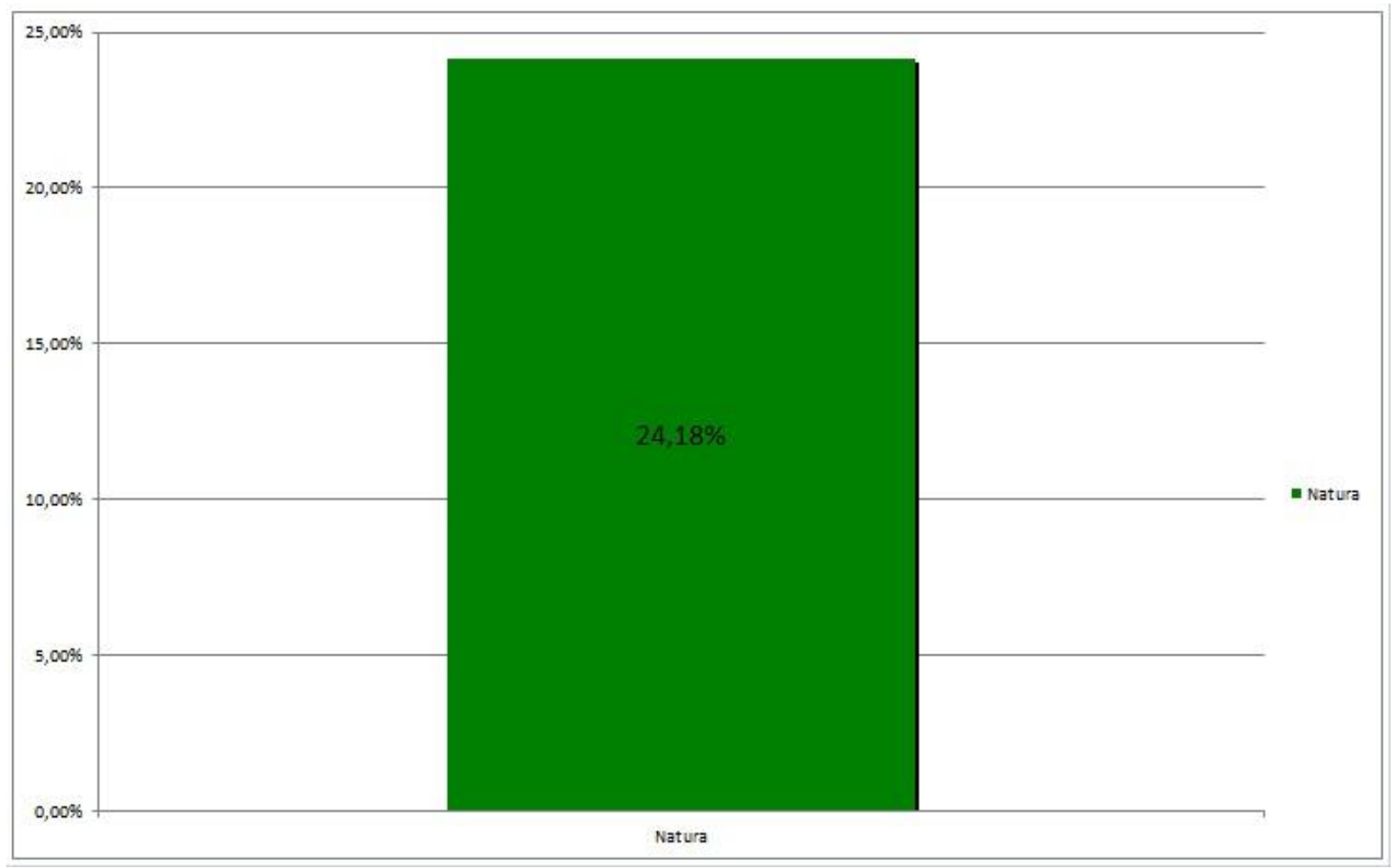

Gráfico 2. EBITDA médio da Natura

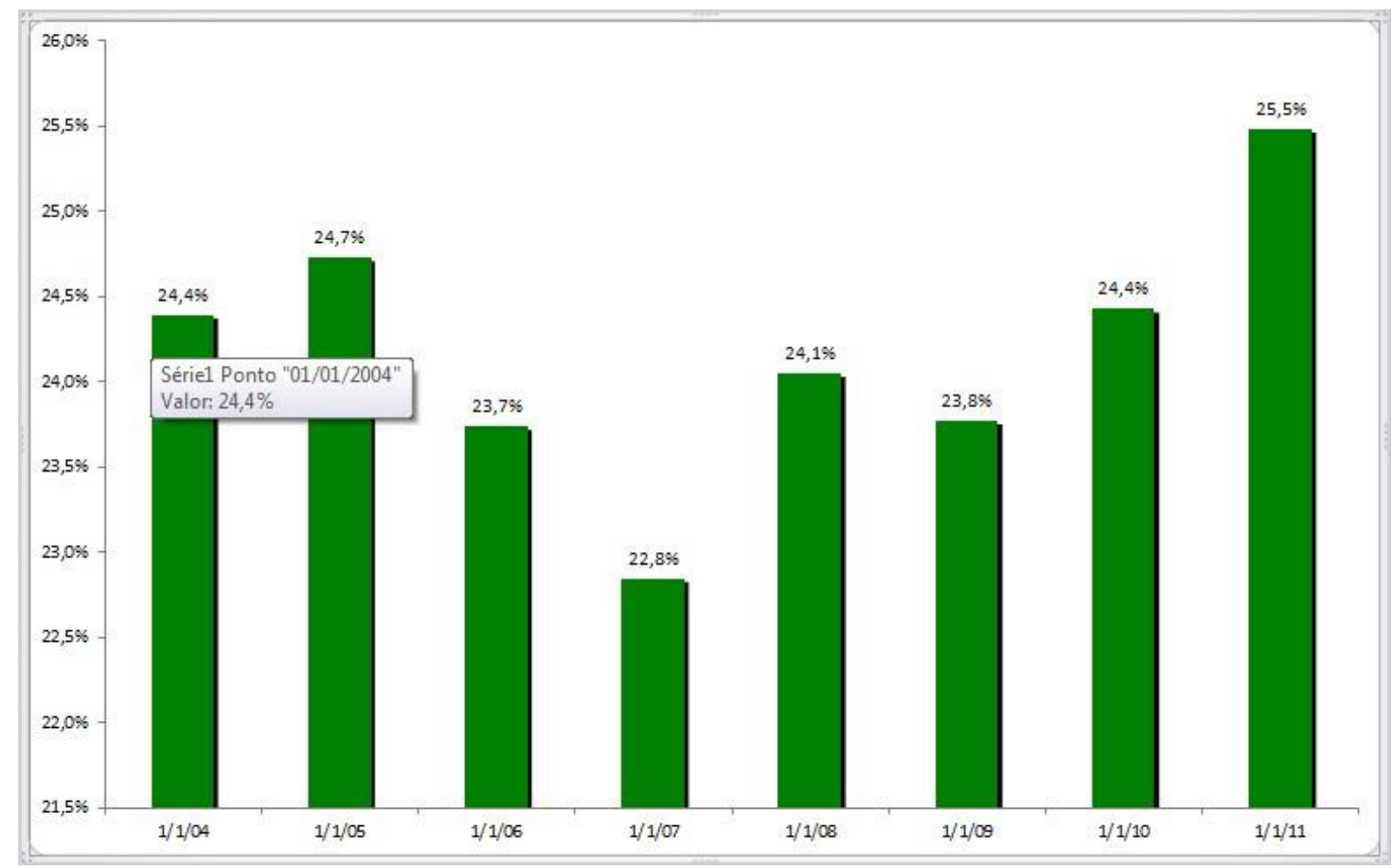

Gráfico 3. Margem EBITDA da Natura para cada ano analisado 


\section{CONSIDERAÇÕES FINAIS}

De acordo com o que foi mencionado anteriormente, lidar com desafios socioambientais tem sido parte da existência da humanidade desde os seus primórdios. Entretanto, as preocupações com o aumento dos problemas ambientais e da desigualdade social e as discussões sobre um desenvolvimento mais sustentável deram origem ao que pode ser chamado de "paradigma da sustentabilidade". Nesse sentido, organizações, órgãos governamentais, entidades não-governamentais e instituições em geral passaram a ser pressionadas pela sociedade a reduzirem seus impactos ambientais e sociais. No contexto empresarial, atualmente, lidar com questões de sustentabilidade tornou-se condição sine qua non para que as empresas transacionem e sobrevivam no mercado, respondendo a demandas da opinião pública. No entanto, as escolhas das empresas sobre a forma de introduzir ações em prol da sustentabilidade podem variar significativamente - considerando sua capacidade de resposta a ser mais reativa ou proativa e sua abordagem em ser mais focada em "salvar a natureza" ou mais focada na "utilização dos recursos de forma sustentável".

Esta pesquisa teve por objetivo analisar os resultados da abordagem de "utilização dos recursos de forma sustentável" sobre a geração de valor de uma firma. Para examinar os impactos dessa abordagem sobre a geração de valor, foram analisados o preço das ações e o desempenho financeiro no mercado de uma empresa da indústria de cosméticos, durante um período de oito anos (de 2004 a 2012). Os resultados ressaltam que a Natura se encaixa na capacidade de resposta proativa (adoção de práticas de modo voluntário) e na abordagem da "utilização dos recursos de forma sustentável", com uma posição de pioneirismo na busca por maneiras para preservar os recursos naturais ao usá-los de forma sustentável, gerando valor econômico através da criação de novos produtos e processos. Através da análise dos dados secundários, constata-se que os esforços de sustentabilidade são parte integrante da estratégia e posicionamento da empresa.

Os resultados sugerem que a adoção de uma abordagem de "utilização dos recursos de forma sustentável" para atuar de acordo com o paradigma da sustentabilidade atual leva a melhores resultados financeiros, tanto em termos de mercado de ações de valorização e em termos da razão entre a receita líquida (a margem EBITDA), indicando maior geração de valor no longo prazo. Em outras palavras, os dados sugerem que a abordagem de "utilização dos recursos de forma sustentável" adotada pela Natura melhorou o desempenho da sua empresa e, portanto, ampliou suas receitas, enquanto que a abordagem para "salvar a natureza", aumentou o tamanho da sua organização e, consequentemente, os seus custos, o que pode explicar os resultados. Embora a firma e a organização da Natura tenham aumentado, a margem EBITDA aponta a expansão do tamanho da firma em relação ao tamanho da organização - os rendimentos da capacidade de inovação (firma) aparecem como superiores ante o custo da estrutura necessária para que a firma funcione (organização).

Nessa circunstância, a premissa de pesquisa 'a abordagem da "utilização de recursos de forma sustentável" leva ao desenvolvimento de novos processos e novos produtos, o que melhora o desempenho da firma, gerando, assim, mais valor' foi confirmada. Nota-se que empresas que adotam esse comportamento proativo ao utilizar os recursos em prol da sustentabilidade transformaram o "ser verde" em uma importante fonte de vantagem competitiva, implantando modelos organizacionais aptos a inserir princípios de sustentabilidade. Pode-se reconhecer que há espaço para debater os resultados encontrados, mas pode-se perceber que a abordagem leva a um resultado diferente do que a média do mercado. Como limitação de pesquisa, aponta-se o estudo de apenas um caso, analisando somente uma das abordagens propostas nesta pesquisa. No que diz respeito a estudos futuros,

GєCont, v.2, n. 1, Floriano-PI, Jan-Jun. 2015. 
sugere-se o aumento do número de empresas para que a premissa de pesquisa seja corroborada e, ainda, pesquisas com mais de um caso para que ambas as abordagens possam ser comparadas.

\section{REFERENCIAS}

ABIHPEC. Associação Brasileira da Indústria de Higiene Pessoal, Perfumaria e Cosméticos. Disponível em <http://www.abihpec.org.br/>. Acesso em 23 jan. 2013.

ABÍLIO, L.C. Parece Perfumaria: o trabalho de um milhão de revendedoras de cosméticos. Anais do XI Congresso Luso Afro Brasileiro de Ciências Sociais. Universidade Federal da Bahia (UFBA). Salvador, 2011.

BARBIERI, J. C.; VASCONCELOS, I. F. G.; ANDREASSI, T.; VASCONCELOS, F. C. Inovação e sustentabilidade: novos modelos e proposições. RAE - Revista de Administração de Empresas, v. 50, n. 2, p.146-154, 2010.

BESSANT, J. Challenges in innovation management. The Internacional Handbook on Innovation, 2003.

CARVALHO, A. P. Gestão Sustentável de Cadeias de Suprimento: análise da indução e implementação de práticas socioambientais por uma empresa brasileira do setor de cosméticos. Tese. Doutorado em Administração. Fundação Getúlio Vargas. São Paulo, 2011.

CARVALHO, A. P.; BARBIERI, J. C. Inovações Socioambientais em Cadeias de Suprimento: um estudo de caso sobre o papel da empresa focal. RAI - Revista de Administração e Inovação, v. 10, n. 1, p. 232-256, jan/mar, 2013.

CASTELLS, M. O Verdejar do Ser: O Movimento Ambientalista. p.141-165, In: CASTELLS, M. O Poder na Identidade. São Paulo: Paz e Terra, 1999.

CASTro, A. E.; COSTA, V. C.; VELTER, A. N.; SCHERER, F. L. Práticas Empresariais Sustentáveis: um estudo comparativo das principais indústrias do setor de cosméticos atuantes no Brasil. Anais do XI Encontro Nacional de Gestão Empresarial e Meio Ambiente, Fortaleza, 2009.

CECCATO, R. C. O Desenvolvimento de Consultores na Natura S/A. Trabalho de Conclusão do Curso de Graduação em Administração. Universidade Regional do Noroeste do Estado do Rio Grande do Sul (UNIJUÍ). Ijuí, 2012.

ClARO, P. B. O.; ClARO, D. P.; AMÂNCIO, R. Entendendo o conceito de sustentabilidade nas organizações. Revista de Administração (FEA-USP), São Paulo, v. 43, n. 4, p.289-300, out/dez, 2008.

CONTADOR, J. C.; STAL, E. A estratégia de internacionalização da Natura: Análise pela óptica da vantagem competitiva. Economia Global e Gestão, v.16, n.2, Lisboa, set. 2011. USA, 2005.

DIAMOND, J. Collapse: how societies choose to fail or succeed. Viking Penguin:

DOSI, G. The nature of the innovative process. In: Dosi, G. et al. (Eds.). Technical change and economic theory. London: Pinter Publishers, 1988. 
DUBOSE, J.; FROST, J.D.; CHAMAEAU, J.A.; VANEGAS, J.A. Sustainable development and technology. In: ELMS, D.; WILKINSIN, D. (Eds.). The Environmentally Educated Engineer. Canterbury: Center for Advanced Engineering, 1995.

EGRI, C. P.; PIENFIELD, L. T. Ser Verde, p.303-304. In: CALDAS, M. et al. (Orgs.). Handbook de Estudos Organizacionais, v. 2. São Paulo: Atlas, 2001.

FERRO, A. F. P.; BONACELli, M. B. M.; ASSAD, A. L. D. Oportunidades tecnológicas e estratégias concorrenciais de gestão ambiental: o uso sustentável da biodiversidade brasileira. Gestão e Produção, v.13, n.3, p.489-501, set/dez, 2006.

FREEMAN, C.; PEREZ, C. Structural crises of adjustment: business cycles and investment behavior. In: Dosi, G. et al. (Eds.). Technical change and economic theory. London: Pinter Publishers, 1988.

HOPWOOD, B.; MELLOR, M.; O’BRIEN, G. Sustainable Development: Mapping Different Approaches. Sustainable Development, v. 13, p.38-52, 2005.

INSTITUTO NATURA. Programa Crer para Ver. Disponível em <http://www.institutonatura.org.br/cpv/crer-para-ver>. Acesso em 18 jan. 2013.

ISE, Índice de Sustentabilidade Empresarial da Bolsa de Valores de São Paulo. Disponível em <https://www.isebvmf.com.br/index.php〉. Acesso em 26 jan. 2013.

KIRON, D.; KRUSCHWITZ, N.; HAANAES, K.; VELKEN, I. S. Sustainability Nears a Tipping Point. MIT Sloan Management Review, v.53, n.2, p.69-74, winter 2012.

MEBRATU, D. Sustainability and Sustainable Development: historical and conceptual review. Environ Impact Asses Review, v. 18, p.493-520, 1998.

NASCIMENTO, P. T. S.; MARX, H. O Sistema de Inovação da Natura. Anais do V Seminários em Administração FEA-USP (SEMEAD). São Paulo, 2001.

NATURA. Relatório Natura, 2011. Disponível em: $<$ http://scf.natura.net/Conteudo/Default.aspx ?MenuStructure=5\&MenuItem=35>. Acesso em 15 dez. 2012.

NATURA EKOS. Disponível em: 〈http://www.naturaekos.com.br/>. Acesso em 16 jan. 2013.

NELSON, R. R.; WINTER, S. G. Uma teoria evolucionária da mudança econômica. Campinas: Editora da Universidade Estadual de Campinas (Série Clássicos da Inovação), 1982, tradução brasileira em 2005.

NORTH, D. Custos de transação, instituições e desempenho econômico. Rio de Janeiro: Instituto Liberal, 1994.

ORSATO, R. J. Competitive Environmental Strategies: when does it pay to be green? California Management Review, v. 48, n. 2, p.127-143, 2006.

PAVITT, K. Some foundations for a theory of large innovating firm. In: Dosi, G. et al. (Eds.). Technology and Enterprise in a Historical Perspective. Oxford, Oxford University Press, 1992.

RIBEIRO, W. C. O Brasil e a Rio+10. Revista do Departamento de Geografia da USP, v. 15, p.37-44, 2002.

SCHUMPETER, J. A. A Teoria do Desenvolvimento Econômico. São Paulo: Ed. Abril, Col. Os Economistas, 1912, tradução brasileira em 1985. 
SCHUMPETER, J. A. Capitalismo, Socialismo e Democracia. Rio de Janeiro: Fundo da Cultura, 1942, tradução brasileira em 1961.

SILVA, G. A. O Impacto da Utilização de Estratégias de Marketing Social na Consolidação da Marca Natura. Trabalho de Conclusão do Curso de Especialização em Marketing e Comunicação. Centro Universitário de Belo Horizonte - UNI-BH. Belo Horizonte, 2007.

TACHIZAWA, T. Gestão ambiental e responsabilidade social corporativa: estratégias de negócio focadas na realidade brasileira. $3^{a}$ ed. São Paulo: Atlas, 2005.

VILHA, A. M.; QUADROS, R. Gestão da Inovação Sob a Perspectiva do Desenvolvimento Sustentável: lições das estratégias e práticas na indústria de higiene pessoal, perfumaria e cosméticos. RAI - Revista de Administração e Inovação, v. 9, n.3, p.28-52, $\mathrm{jul} / \mathrm{set}, 2012$.

WCED, World Commission on Environment and Development. Our Common Future. London: Oxford University Press, 1987.

YAMIM, A. P. ; ALVES, A. P. F. ; PANTOJA, F. C. F. ; SILVA, M. E. Uma relação Toma Lá, Dá Cá! A interface vendedor-consumidor na compreensão dos atributos valorizados e das motivações de compra. In: Anais do $6^{\mathbf{0}}$ Congresso Latino-Americano no Varejo, São Paulo, 2013. 